\title{
Structural Changes over a Short Period Are Associated with Functional Assessments in Rheumatoid Arthritis
}

\author{
Tomohiro Shimizu, Ana Cruz, Matthew Tanaka, Kenji Mamoto, Valentina Pedoia, \\ Andrew J. Burghardt, Ursula Heilmeier, Thomas M. Link, Jonathan Graf, John B. Imboden, \\ and Xiaojuan Li
}

ABSTRACT. Objective. To investigate the correlation between changes in radiological quantitative assessment with changes in clinical and functional assessment from baseline to 3 months in patients with rheumatoid arthritis (RA).

Methods. Twenty-eight patients with RA [methotrexate (MTX) and anti-tumor necrosis factor- $\alpha$ $(\mathrm{TNF}-\alpha)$ group with high disease activity $(\mathrm{n}=18)$; and MTX group with low disease activity $(\mathrm{n}=10)]$ underwent assessments at baseline and 3 months: clinical [28-joint count Disease Activity Score (DAS28)], functional [Health Assessment Questionnaire (HAQ) and Michigan Hand Outcome Questionnaire (MHQ)], and imaging-based [3 Tesla magnetic resonance imaging (MRI) and high-resolution peripheral quantitative computed tomography (HR-pQCT)]. MR images were evaluated semiquantitatively [RA MRI scoring (RAMRIS)] and quantitatively for the volume of synovitis and bone marrow edema (BME) lesions. Erosion volumes were measured using HR-pQCT. Results. After 3 months, the anti-TNF- $\alpha$ group demonstrated an improvement in disease activity through DAS28, HAQ, and MHQ. MRI showed significant decreases in synovitis and BME volume for the anti-TNF- $\alpha$ group, and significant increases in the MTX group. HR-pQCT showed significant decreases in bone erosion volume for the anti-TNF- $\alpha$ group, and significant increases in the MTX group. No significance was observed using RAMRIS. Changes in synovitis, BME, and erosion volumes, but not RAMRIS, were significantly correlated with changes in DAS28, HAQ, and MHQ. Conclusion. Quantitative measures were more sensitive than semiquantitative grading when evaluating structural and inflammatory changes with treatment, and were associated with patient clinical and functional outcomes. Multimodality imaging with 3T MRI and HR-pQCT may provide promising biomarkers that help determine disease progression and therapy response. (First Release February 15 2019; J Rheumatol 2019;46:676-84; doi:10.3899/jrheum.180496)

Key Indexing Terms:
RHEUMATOID ARTHRITIS
$\begin{aligned} & \text { HIGH-RESOLUTION PERIPHERAL QUANTITATIVE COMPUTED TOMOGRAPHY } \\ & \text { QUANTITATIVE IMAGING MEASURES }\end{aligned}$
MULTIMODALITY IMAGING

From the Department of Radiology and Biomedical Imaging, Musculoskeletal Quantitative Imaging Research, and the Department of Medicine, Division of Rheumatology, and the School of Pharmacy, at the University of California, San Francisco (UCSF), San Francisco, California; Department of Biomedical Engineering, Program of Advanced Musculoskeletal Imaging (PAMI), Cleveland Clinic, Cleveland, Ohio; Department of Orthopaedic Surgery, Faculty of Medicine and Graduate School of Medicine, Hokkaido University, Sapporo, Japan.

This study was supported by UCB Pharmaceutical Inc. (Xiaojuan Li). T. Shimizu, MD, PhD, Department of Radiology and Biomedical Imaging, Musculoskeletal Quantitative Imaging Research, UCSF, and Department of Orthopaedic Surgery, Faculty of Medicine and Graduate School of Medicine, Hokkaido University; A. Cruz, BS, Department of Radiology and Biomedical Imaging, Musculoskeletal Quantitative Imaging Research, and School of Pharmacy, UCSF; M. Tanaka, BS, Department of Radiology and Biomedical Imaging, Musculoskeletal Quantitative Imaging Research, UCSF; K. Mamoto, MD, PhD, Department of Radiology and Biomedical Imaging, Musculoskeletal Quantitative Imaging Research, UCSF, and Department of Biomedical Engineering, PAMI, Cleveland Clinic; V. Pedoia, PhD, Department of Radiology and Biomedical Imaging, Musculoskeletal Quantitative Imaging Research, UCSF; A.J. Burghardt, $B S$, Department of Radiology and Biomedical Imaging, Musculoskeletal Quantitative Imaging Research, UCSF; U. Heilmeier, MD, Department of Radiology and Biomedical Imaging, Musculoskeletal Quantitative Imaging

\begin{abstract}
Research, UCSF; T.M. Link, MD, PhD, Department of Radiology and Biomedical Imaging, Musculoskeletal Quantitative Imaging Research, UCSF; J. Graf, MD, Department of Medicine, Division of Rheumatology, UCSF; J.B. Imboden, MD, Department of Medicine, Division of Rheumatology, UCSF; X. Li, PhD, Department of Radiology and Biomedical Imaging, Musculoskeletal Quantitative Imaging Research, UCSF, and Department of Biomedical Engineering, PAMI, Cleveland Clinic.

Address correspondence to Dr. T. Shimizu, Department of Orthopaedic Surgery, Faculty of Medicine and Graduate School of Medicine, Hokkaido University, Sapporo, Japan.E-mail: simitom@wg8.so-net.ne.jp

Accepted for publication October 24, 2018.
\end{abstract}

Rheumatoid arthritis (RA) is a progressive, chronic autoimmune disease characterized by synovitis that can cause cartilage damage, bone erosion, and ultimately joint deformities that may affect functioning $1,2,3$. In the absence of effective therapy, structural abnormalities usually progress and eventually lead to joint deformities and severe functional impairment with disability. Current guidelines from the American College of Rheumatology (ACR) recommend the 
use of clinical and functional assessments such as the 28-joint Disease Activity Score (DAS28) and the Health Assessment Questionnaire (HAQ) to determine RA progression and therapy response ${ }^{4}$. In addition, the Michigan Hand Outcome Questionnaire (MHQ) is one of the most common evaluation tools for hand-specific functions ${ }^{5}$; however, to the best of our knowledge, only a few studies about the MHQ have investigated the association with clinical response and structural assessment in patients with $\mathrm{RA}^{6,7}$.

When conducting structural assessments using conventional radiography, the Sharp score is considered the reference standard to assess joint damage of the hand and foot $^{8}$. However, this method does not visualize inflammation nor is it sensitive enough to measure both early and late erosive changes in patients with mild and moderate RA severity. Magnetic resonance imaging (MRI), on the other hand, provides reproducible measurements of joint inflammation and is superior to radiography in monitoring RA progression $^{9,10}$. The Outcome Measures in Rheumatology Clinical Trials (OMERACT) RA MRI scoring (RAMRIS) system is a semiquantitative method that was developed to assess inflammatory and destructive changes in the hands and wrists of patients with RA ${ }^{11,12,13}$. This MR-based OMERACT RAMRIS system has been widely accepted as the gold standard for scoring structural damage on MRI images in patients with RA. Moreover, several studies have reported that the RAMRIS score was associated with patient-reported outcomes and could predict subsequent radiographic progression ${ }^{14,15,16}$. However, a recent systematic review showed that the timing of the measurements to meet validation criteria was variable; more specifically, 24-52 weeks might be necessary for the RAMRIS score for erosion to discriminate regarding worsening joint damage ${ }^{17}$. Therefore, the RAMRIS score may be limited in detecting the structural changes and assessing early treatment response over a short time period such as 3 months.

Our group previously found that semiautomatic quantitative measurements of synovitis and bone marrow edema (BME) lesions in the wrist of patients with RA using 3 Tesla (3T) MRI showed excellent reproducibility and significant correlations with the standard RAMRIS score ${ }^{18,19}$. In addition to MRI, high-resolution peripheral quantitative computed tomography (HR-pQCT) is an emerging tool that provides a highly sensitive and reliable method to assess structural bone damage and joint space volume in patients with $\mathrm{RA}^{20-25}$. Therefore, combining MRI and HR-pQCT may help even more in evaluating structural and inflammatory joint abnormalities. This multimodal approach may also help in optimizing treatment strategies in subjects with RA.

The goal of our study was to investigate the correlation between changes in quantitative radiological structural joint assessments evaluated through MRI and HR-pQCT, and changes in clinical and functional assessments in patients with RA as evaluated using DAS28, HAQ, and MHQ. These 2 patient groups were followed in our study over a 3-month period: (1) patients with low disease activity while taking methotrexate (MTX; MTX group); and (2) patients with high disease activity who had just begun anti-tumor necrosis factor- $\alpha$ (anti-TNF- $\alpha$ ) therapy (TNF- $\alpha$ group). We hypothesized that multimodality imaging using quantitative MRI and HR-pQCT would be more sensitive and powerful in evaluating disease progression and therapy response in patients with RA and would also be associated with clinical and functional variables.

\section{MATERIALS AND METHODS}

Patients. The Institutional Review Board reviewed and approved our study and all patients provided written consent prior to study initiation (IRB no. 12-10418). Using the 2010 ACR/European League Against Rheumatism (ACR/EULAR) classification criteria for $\mathrm{RA}^{26}, 28$ patients were enrolled and divided into 2 treatment groups by the DAS28-erythrocyte sedimentation rate (ESR) score. Ten patients with DAS28-ESR $\leq 3.2$ were continued to MTX treatment (MTX group), and 18 patients with DAS28-ESR > 3.2 were initiated on certolizumab pegol, a monoclonal antibody against TNF- $\alpha$, in addition to their MTX regimen (TNF- $\alpha$ group). At baseline (prior to initiation of the anti-TNF- $\alpha$ treatment) and 3 months, each patient underwent clinical (DAS28), functional (HAQ and MHQ), and structural (imaging of the dominant hand/wrist by 3T MRI and HR-pQCT) assessments.

Clinical assessment. At the baseline and 3-month visit, each patient was seen and examined clinically by a certified rheumatologist (JG and JBI). The clinical examination included the assessment of the visual analog scale (VAS) of disease activity, a 28-joint tender joint count, a 28-joint swollen joint count (SJC28), and a blood draw and serum testing for both C-reactive protein (CRP) and ESR. At each visit, a DAS28 score was then calculated from the above-stated components ${ }^{27}$.

Functional assessments. At each visit, the HAQ and MHQ self-assessment questionnaires were administered to evaluate the patient's subjective rating of RA severity. The HAQ measures the total body functional status (for both upper and lower extremities) using 8 different categories of daily living, such as the ability to grip, walk, eat, and groom oneself, and others. The highest score from each category was summed and divided by 8 to obtain the final score $^{28}$. The MHQ is a self-administered questionnaire that contains 37 items. The questionnaire assesses hand/wrist function in 6 domains: overall hand function, activities of daily living, pain, work performance, esthetics, and patient satisfaction with function. Results of each domain were converted to a score scale ranging from 0 to 100 , where a higher score indicated no impairment - with the exception of the pain scale, where a lower score signified less pain. The mean of the 6 categories was taken, after reversing the pain scale, to obtain the final score ${ }^{29}$.

MRI and image analysis. MRI scans of the dominant wrist were obtained using a 3T MR scanner (MR 750 Wide Bore; GE Healthcare) with an 8-channel phased array wrist coil (Invivo). Patient positioning followed a strict standard protocol. While in a supine position, the patients rested their arms at their sides. Using padding, both elbows and wrists were immobilized to minimize movement and improve reproducibility. BME were evaluated using coronal T2-weighted iterative decomposition of water and fat with echo asymmetry and least squares estimation (IDEAL) fast spin echo (FSE) water images [repetition time (TR)/echo time $(\mathrm{TE})=3500 / 50 \mathrm{~ms}$, in-plane resolution $=0.2 \mathrm{~mm}$, slice thickness $=2 \mathrm{~mm}]$. Bone erosions and joint space narrowing (JSN) were assessed using coronal and axial T1-weighted IDEAL spoiled gradient echo images $(\mathrm{TR} / \mathrm{TE}=15.3 / 2.9 \mathrm{~ms}$, in-plane resolution $=0.2$, slice thickness $=1 \mathrm{~mm})$. Synovitis was evaluated through coronal T1-weighted IDEAL FSE images $(\mathrm{TR} / \mathrm{TE}=600 / 9.9 \mathrm{~ms}$, in-plane resolution $=0.44 \mathrm{~mm}$, slice thickness $=2 \mathrm{~mm}$ ) before and after contrast agent injection (Gd-DPTA with a dose of $0.2 \mathrm{mmol} / \mathrm{kg}$ ).

Personal non-commercial use only. The Journal of Rheumatology Copyright (c) 2019. All rights reserved. 
A board-certificated musculoskeletal radiologist (TL) used the OMERACT RAMRIS system to evaluate all MRI images. Synovitis was assessed in 3 wrist regions (the distal radioulnar joint, the radiocarpal joint, and the intercarpal and carpometacarpal joints) and the scale was 0-3. For evaluations of BME and erosion, each bone (wrists: distal radius, distal ulna, carpal bones, metacarpal bases) was scored separately. The scale of BME was $0-3$ based on the proportion of BME, and the scale of bone erosion was 0-10. JSN was assessed in 7 joints (carpometacarpal 2 and 3, trapezoid-scaphoid, capitate-lunate, hamate-triquetrum, radius-scaphoid, and radio-lunate) and the scale was $0-4{ }^{13}$. RAMRIS scoring was performed blinded to the clinical data and previous radiology reports. Intrareader reproducibility was performed and ICC was excellent (ICC $=0.903, p<0.001$ ).

The volume of synovitis and BME were semiautomatically quantified through T2-weighted FSE IDEAL images and post-Gd T1-weighted FSE IDEAL images, respectively, by 3 independent readers (TS, KM, and MST), using in-house developed MATLAB-based software ${ }^{19}$. Interreader reproducibility was performed and ICC was excellent (ICC $=0.901, \mathrm{p}<0.001$ ). It took 1-2 hours to assess the images and then quantify for MRI.

We took $1-2 \mathrm{~h}$ to assess the images and then quantify for MRI analysis, and around $3 \mathrm{~h}$ to assess the images and then quantify for HR-pQCT.

$H R-p Q C T$ and image analysis. Images of the dominant hand and wrist were obtained using a first-generation HR-pQCT system (XtremeCT, Scanco Medical AG) in which the wrist and distal radius were recorded ${ }^{22}$. The wrist acquisition was performed in the standard forearm cast provided by the manufacturer with the hand in a thumb-up orientation. The wrist scan covered $27.06 \mathrm{~mm}$ (330 slices) with a total scan time of about 9 min and an effective dose of $12.6 \mu \mathrm{SV}^{30}$. Bone erosions were evaluated from the HR-pQCT images at the wrist following the recommended definitions and procedures developed by the Study GrouP for XTrEme-CT in Rheumatoid Arthritis (SPECTRA) ${ }^{31}$. Erosion was defined as a sharply demarcated cortical break spanning 2 or more consecutive axial slices and confirmed in the sagittal or coronal planes. Erosions were defined as sharply demarcated juxtaarticular focal bone lesions with a cortical break (loss of cortex) in at least 2 adjacent slices. Bone erosion volume of the distal radius, lunate, and scaphoid were automatically measured by stacking the axial 2-D slices of bone erosion segmented by 2 rheumatologists independently (TS and KM) using the open-source digital imaging and communications in medicine (DICOM) viewer OsiriX 7.0 (Nema). They were blinded to the clinical data and previous radiology reports. Measurements of all erosions were performed 3 times with a 4-week interval. Interreader and intrareader reproducibility was performed and intraclass and interclass correlation coefficient were excellent (interreader $=0.802, \mathrm{p}=0.010 ;$ intrareader $=0.933$, $\mathrm{p}<0.001)$.

Three-D measures of mean joint space volume (JSV) in the radio-lunate and radio-scaphoid joints were measured using an automated pipeline developed in our group ${ }^{32}$. It took around $3 \mathrm{~h}$ to assess the images and then quantify for HR-pQCT.

Statistical analysis. Intra-individual differences between baseline and 3-month parameters were compared using a paired t test. Linear regression models adjusted for age, sex, disease duration, and therapy (anti-TNF- $\alpha$ added or not) were built to evaluate the associations between the changes from 3 months to baseline of quantitative radiological assessments evaluated by MRI and HR-pQCT, and changes in clinical (DAS28) and functional (HAQ and MHQ) assessments. Associations between the changes from 3 months to baseline of quantitative radiological assessments evaluated by MRI and HR-pQCT, and changes in clinical (DAS28) and functional (HAQ and MHQ) assessments in each group separately were calculated using Spearman rank correlation. Associations were considered statistically significant for $\mathrm{p}$ values $<0.05$. All statistical analyses were performed using SPSS (IBM).

\section{RESULTS}

Clinical and functional assessments. Table 1 summarizes patient demographics at baseline for both groups. Table 2
Table 1. Patient characteristics at baseline

\begin{tabular}{lccc}
\hline Characteristics & $\begin{array}{c}\text { All Patients, } \\
\mathrm{n}=28\end{array}$ & $\begin{array}{c}\text { MTX Group, } \\
\mathrm{n}=10\end{array}$ & $\begin{array}{c}\text { TNF- } \alpha \text { Group, } \\
\mathrm{n}=18\end{array}$ \\
\hline Age, yrs & $51.7(15.2)$ & $58.6(15.8)$ & $47.8(13.8)$ \\
Sex, female:male & $23: 5$ & $7: 3$ & $16: 2$ \\
Race, $\mathrm{n}$ & & & \\
$\quad$ White & 12 & 6 & 6 \\
Hispanic or Latino & 7 & 2 & 5 \\
Pacific Islander & 1 & 0 & 1 \\
African American & 2 & 0 & 2 \\
$\quad$ Declined to report & 6 & 2 & 4 \\
Body mass index, $\mathrm{kg} / \mathrm{m}^{2}$ & $28.6(8.1)$ & $24.5(5.5)$ & $30.9(8.5)$ \\
RA onset, yrs & $5.6(5.4)$ & $7.1(5.2)$ & $4.7(5.5)$ \\
MTX dose, mg & $14.8(7.3)$ & $13.0(7.9)$ & $16.2(6.4)$ \\
Other DMARD, $\mathrm{n}$ & $1(\mathrm{SSZ})$ & 0 & $1(\mathrm{SSZ})$ \\
Prednisone dose, $\mathrm{mg}$ & $4.5(3.8)$ & $1.3(4.1)$ & $6.3(3.3)$ \\
mTSS score & $30.7(32.0)$ & $26.5(15.6)$ & $33.1(33.9)$ \\
& & & \\
\hline
\end{tabular}

Data presented as mean (SD) unless otherwise indicated. MTX: methotrexate; TNF- $\alpha$ : tumor necrosis factor- $\alpha$; DMARD: disease-modifying antirheumatic drugs; mTSS: modified total Sharp score; SSZ: sulfasalazine; RA: rheumatoid arthritis.

summarizes patients' clinical and functional features at baseline and 3 months. Note that 2 patients ( 1 from each group) were lost to followup at the 3 -month point. The significant decrease in DAS28 scores $(\mathrm{p}<0.001$; and overall improvement in disease activity scores) was evident throughout all subscores, and especially pronounced in the physician VAS score $(\mathrm{p}=0.010)$ and SJC $(\mathrm{p}<0.001)$. Over the course of 3 months, among the anti-TNF- $\alpha$ treatment patients, 5 patients qualified as good responders, 11 were moderate, and 1 was a nonresponder in accordance with the EULAR response criteria ${ }^{33}$. Additionally, the TNF- $\alpha$ group displayed significant improvements in functional assessments, evident by the significant decrease in HAQ scores $(\mathrm{p}<0.001)$ and significant increase in MHQ ( $\mathrm{p}<0.001)$.

Wrist synovitis evaluation using $3 T$ MRI. The MRI-based RAMRIS grading showed no significant changes in global wrist synovitis for the MTX group, and a trend of decreasing wrist synovitis for the TNF- $\alpha$ group from baseline to 3 months ( $p=0.064$; Figure $1 \mathrm{~A}$ and $1 \mathrm{~B})$. However, the global wrist synovitis volume quantification showed a significant increase for the MTX group ( $\mathrm{p}=0.038)$ and a significant decrease of the TNF- $\alpha$ group ( $p<0.001$; Figure 1C). In specific regions such as the intercarpal region, the TNF- $\alpha$ group showed a significant decrease of the RAMRIS synovitis score from baseline to 3 months $(p=0.015$; Figure 1B). The RAMRIS wrist synovitis subscores for the radioulnar, radiocarpal, and total region showed a decrease of synovitis, albeit statistically insignificant, in the TNF- $\alpha$ group from baseline to 3 months. On the other hand, we observed that in the TNF- $\alpha$ group, the quantitatively assessed wrist synovitis volume significantly decreased in all regions (radiocarpal region: $p=0.011$; radioulnar region: $p=0.023$; intercarpal region: $\mathrm{p}=0.023$; region surrounding the extensor

Personal non-commercial use only. The Journal of Rheumatology Copyright $\odot$ 2019. All rights reserved. 
Table 2. Clinical and functional scores at baseline and 3 months.

\begin{tabular}{|c|c|c|c|c|c|c|}
\hline \multirow[t]{2}{*}{ Variables } & \multicolumn{3}{|c|}{ MTX Group } & \multicolumn{3}{|c|}{ TNF- $\alpha$ Group } \\
\hline & Baseline & 3 Mos & $\mathrm{p}$ & Baseline & $3 \mathrm{Mos}$ & $\mathrm{p}$ \\
\hline \multicolumn{7}{|l|}{ Clinical assessments } \\
\hline Patient & $7.2(14.4)$ & $18.4(26.7)$ & 0.213 & $58.6(18.7)$ & $42.2(30.2)$ & 0.010 \\
\hline Physician & $12.9(11.0)$ & $14.1(12.6)$ & 0.459 & $41.7(10.7)$ & $26.9(11.9)$ & 0.004 \\
\hline Tender joint count & $0.7(1.1)$ & $1.0(1.3)$ & 0.438 & $10.1(6.3)$ & $4.9(9.4)$ & 0.063 \\
\hline $\mathrm{ESR}, \mathrm{mm} / \mathrm{h}$ & $17.4(21.1)$ & $21.0(18.3)$ & 0.435 & $34.9(26.2)$ & $29.7(21.6)$ & 0.490 \\
\hline DAS28-CRP & $1.9(0.6)$ & $2.4(0.8)$ & 0.033 & $5.2(0.9)$ & $3.6(1.0)$ & $<0.001$ \\
\hline DAS28-ESR & $2.0(0.9)$ & $2.6(0.9)$ & 0.106 & $5.9(1.1)$ & $3.8(1.2)$ & $<0.001$ \\
\hline \multicolumn{7}{|l|}{ Functional assessments } \\
\hline HAQ & $0.5(0.6)$ & $0.7(0.8)$ & 0.084 & $1.6(0.6)$ & $1.0(0.7)$ & $<0.001$ \\
\hline MHQ & $79.6(19.1)$ & $81.6(23.2)$ & 0.665 & $44.5(15.8)$ & $61.2(20.7)$ & $<0.001$ \\
\hline
\end{tabular}

Data presented as mean (SD). Values in bold face are statistically significant. MTX: methotrexate; TNF- $\alpha$ : tumor necrosis factor- $\alpha$; CRP: C-reactive protein; ESR: erythrocyte sedimentation rate; DAS28: 28-joint count Disease Activity Score; HAQ: Health Assessment Questionnaire; MHQ: Michigan Hand Outcome Questionnaire.

A
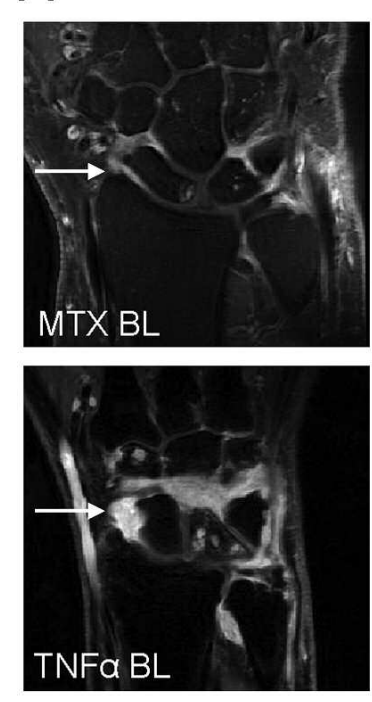

B
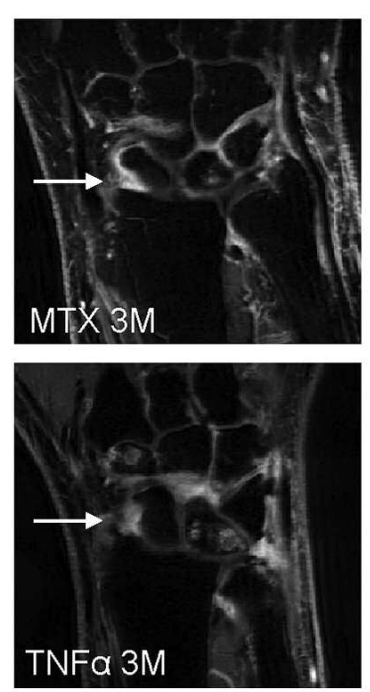

RAMRIS synovitis score
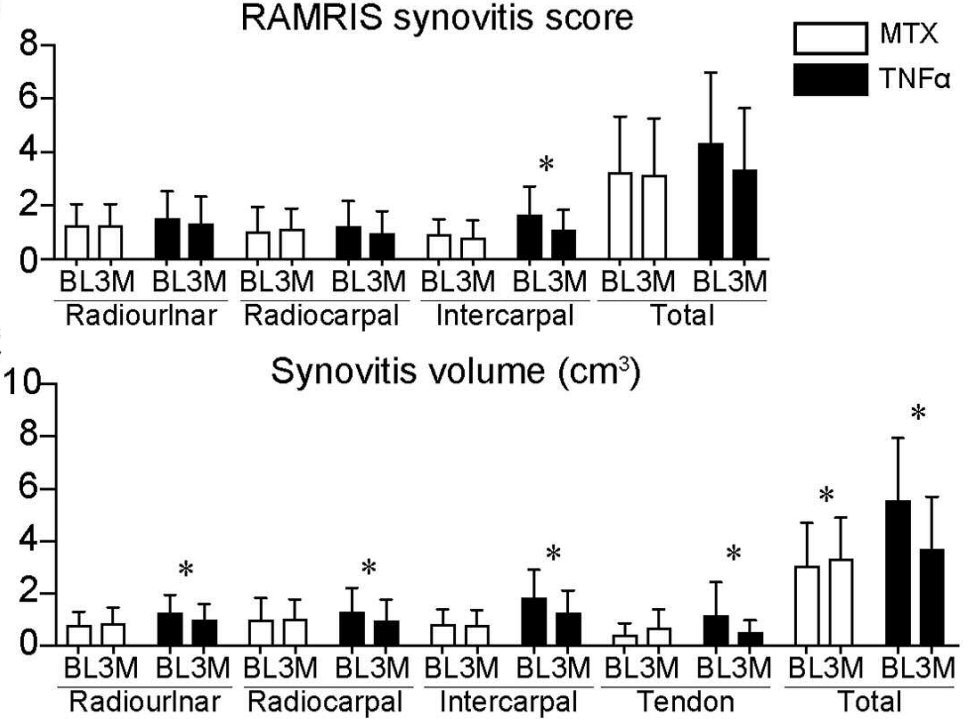

Figure 1. A. Post-gadolinium coronal T1-weighted iterative decomposition of water and fat with echo asymmetry and least-squares estimation (IDEAL) fast spin echo images showing synovitis at baseline and 3 months in an MTX-only patient and an MTX + anti-TNF- $\alpha$ patient. White arrows show synovitis. B. Mean RAMRIS synovitis score at baseline and 3 months for each group. C. Mean synovitis volume at baseline and 3 months for each group. * Significant differences $(\mathrm{p}<0.05)$ from baseline to 3 months. MTX: methotrexate; BL: baseline; $3 \mathrm{M}: 3$ months; TNF- $\alpha$ : tumor necrosis factor- $\alpha$; RAMRIS: rheumatoid arthritis magnetic resonance imaging scoring.

tendons: $\mathrm{p}=0.041$ ) from baseline to 3 months (Figure 1C). Wrist BME evaluation using $3 T$ MRI. The RAMRIS grading showed no change in global BME for the MTX group, and a trend of decreasing global BME for the TNF- $\alpha$ group from baseline to 3 months ( $p=0.078$; Figure $2 A$ and $2 B$ ). The global BME volume quantification showed a significant increase for the MTX-only group $(\mathrm{p}=0.038)$ and a significant decrease of the anti-TNF- $\alpha$ group $(p=0.023$; Figure 2C). In specific regions, the RAMRIS BME score in each individual region showed a decrease, albeit statistically insignificant, in the anti-TNF- $\alpha$ group from baseline to 3 months (Figure 2B). On the other hand, BME volume quantified by software showed significant decreases in the distal carpal row region $(p=0.036)$ of the anti-TNF- $\alpha$ group from baseline to 3 months (Figure 2C). In addition, BME volume quantified by software showed significant increases in the proximal carpal row region $(\mathrm{p}=0.026)$ in the MTX-only group.

Bone erosion and joint space evaluation by MRI and $H R-p Q C T$. The MTX group showed an increase in bone

$$
\text { Personal non-commercial use only. The Journal of Rheumatology Copyright @ } 2019 \text {. All rights reserved. }
$$


erosion at the wrist from baseline to 3 months, while the TNF- $\alpha$ group showed a decrease (Figure 3A). However, when using RAMRIS bone erosion and JSN scores at the wrist, we did not detect any significant differences in either groups from baseline to 3 months (Figure 3B and 3D). On the other hand, in the quantitative analysis using HR-pQCT
A
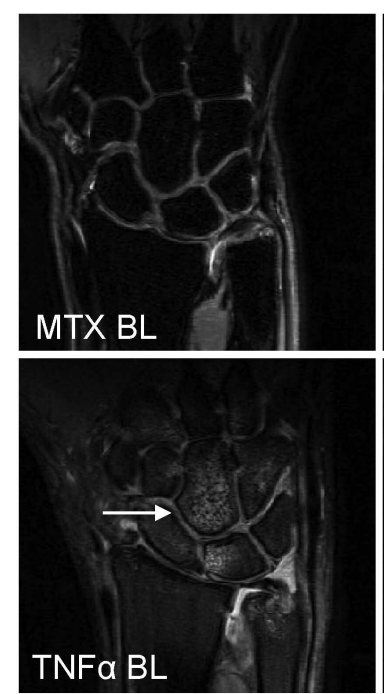

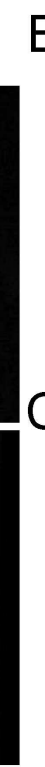

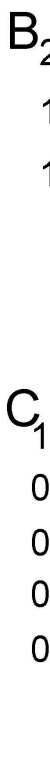

RAMRIS edema score
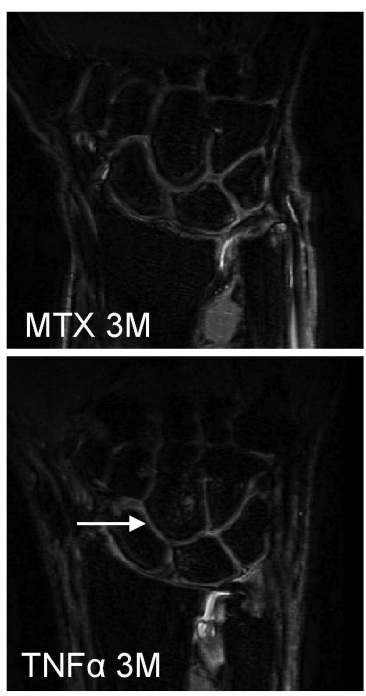

BMEL volume $\left(\mathrm{cm}^{3}\right)$

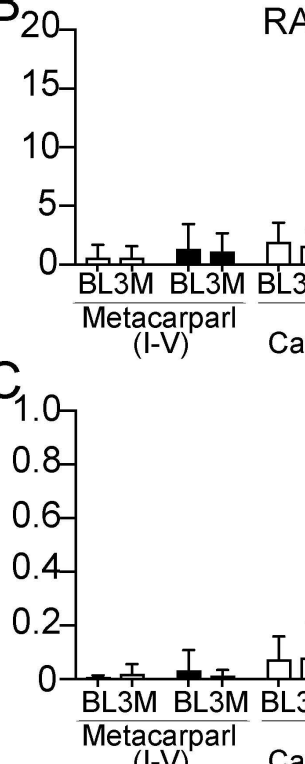

$(\mathrm{I}-\mathrm{V})$

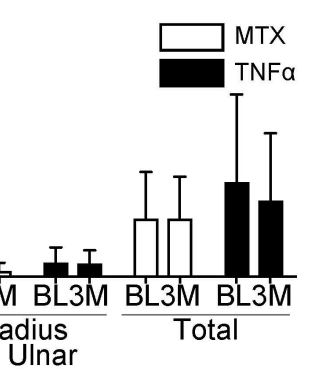

Figure 2. A. T2-weighted iterative decomposition of water and fat with echo asymmetry and least-squares estimation (IDEAL) fast spin echo water images showing BME at baseline and 3 months in an MTX-only patient and an MTX + anti-TNF- $\alpha$ patient. White arrows show BME. B. Mean RAMRIS BME score at baseline and 3 months for each group. C. Mean BME volume at baseline and 3 months for each group. * Significant differences from baseline to 3 months. BME: bone marrow edema; MTX: methotrexate; BL: baseline; 3M: 3 months; TNF- $\alpha$ : tumor necrosis factor- $\alpha$; RAMRIS: rheumatoid arthritis magnetic resonance imaging scoring.
A
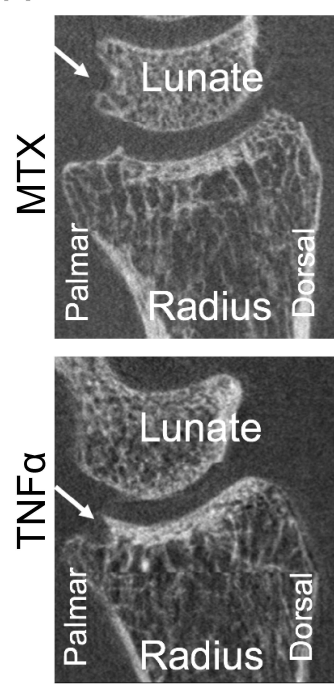

Baseline
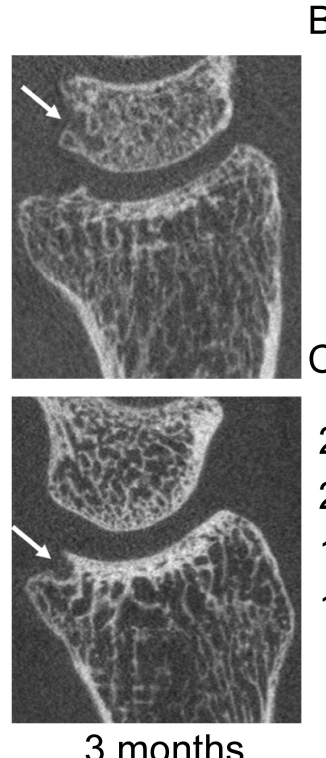

B MRI erosion score D

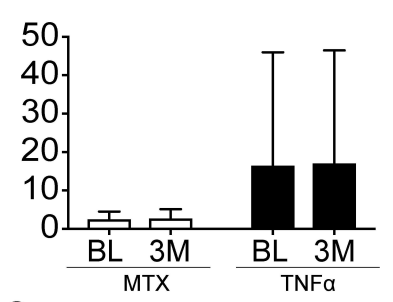

C
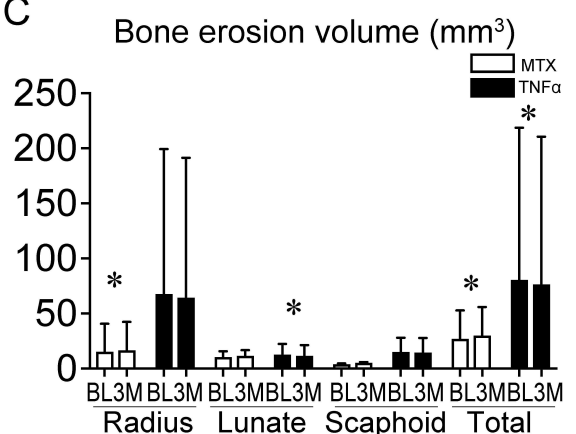

MRI JSN score

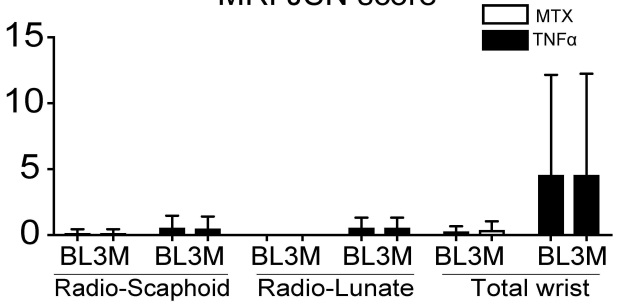

E

Joint space volume $\left(\mathrm{mm}^{3}\right)$

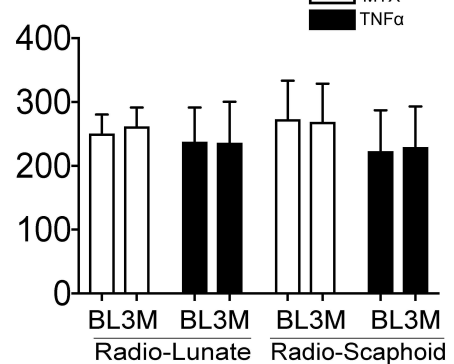

Figure 3. A. HR-pQCT images showing bone erosion at baseline and 3 months in an MTX-only patient and an MTX + anti-TNF- $\alpha$ patient. White arrows depict erosion. B. Mean RAMRIS bone erosion at baseline and 3 months for each group. C. Mean bone erosion volume at baseline and 3 months for each group. D. Mean RAMRIS JSN score at baseline and 3 months for each group. E. Mean joint space volume at the wrist at baseline and 3 months for each group. * Significant differences from baseline to 3 months. HR-pQCT: high-resolution peripheral quantitative computed tomography; MTX: methotrexate; BL: baseline; $3 \mathrm{M}$ : 3 months; TNF- $\alpha$ : tumor necrosis factor- $\alpha$; MRI: magnetic resonance imaging; JSN: joint space narrowing; RAMRIS: rheumatoid arthritis magnetic resonance imaging scoring.

Personal non-commercial use only. The Journal of Rheumatology Copyright @ 2019 . All rights reserved. 
images, the MTX group showed significant increases in bone erosion volume at the distal radius and the total from baseline to 3 months (radius: $p=0.013$ and total: $p=0.001$ ) regardless of low disease activity; while the TNF- $\alpha$ group showed a decrease in bone erosion volume at the lunate and total from baseline to 3 months (lunate: $p=0.001$ and total: $p=0.025$; Figure 3C). In joint space evaluation, there were no differences in either group between baseline and 3 months (Figure 3E).

Correlations between functional and structural assessments. Table 3 summarizes correlations between changes of DAS28, HAQ, and MHQ scores versus radiological assessments measured by quantitative measurements from baseline to 3 months. Percent changes in volume of synovitis, BME, and bone erosion for all patients had statistically significant positive correlations with changes of DAS28-CRP and HAQ score from baseline to 3 months. Percent change in volume of BME had a significant correlation with change of MHQ-patient satisfaction. Percent change in volume of erosion had significant correlations with changes of HAQ-arising, HAQ-grip, MHQ-total, and MHQ-pain. Percent change in volume of JSV of the wrist had a significant correlation with change of HAQ-walking. On the other hand, no correlations were found between changes in RAMRIS score, DAS28 score, HAQ-total, and MHQ-total. Spearman rank correlation coefficients between changes in quantitative MRI and HR-pQCT measures and changes in DAS28, HAQ, and MHQ scores were also calculated for patients in each group separately (data not shown).

\section{DISCUSSION}

To our knowledge, this observational, longitudinal cohort

Table 3. Associations between quantitative structural changes and clinical and functional changes.

\begin{tabular}{|c|c|c|c|c|}
\hline Variables & $\% \Delta$ Synovitis Volume & $\% \triangle \mathrm{BME}$ Volume & $\% \Delta$ Erosion Volume & $\% \Delta \mathrm{JSV}$ Wrist \\
\hline$\triangle \mathrm{DAS} 28$ & $\beta=0.629$ & $\beta=0.323$ & $\beta=0.396$ & $\beta=0.019$ \\
\hline ESR & $p=0.004$ & $\mathrm{p}=0.171$ & $\mathrm{p}=0.083$ & $\mathrm{p}=0.919$ \\
\hline$\triangle \mathrm{DAS} 28$ & $\beta=0.647$ & $\beta=0.524$ & $\beta=0.478$ & $\beta=-0.029$ \\
\hline CRP & $p=0.001$ & $p=0.037$ & $p=0.045$ & $\mathrm{p}=0.875$ \\
\hline$\triangle \mathrm{HAQ}$ & $\beta=0.623$ & $\beta=0.592$ & $\beta=0.496$ & $\beta=0.176$ \\
\hline Total & $p=0.027$ & $p=0.033$ & $p=0.043$ & $\mathrm{p}=0.485$ \\
\hline$\triangle \mathrm{HAQ}$ & $\beta=0.201$ & $\beta=0.391$ & $\beta=0.320$ & $\beta=-0.126$ \\
\hline Dressing & $\mathrm{p}=0.592$ & $\mathrm{p}=0.107$ & $\mathrm{p}=0.296$ & $\mathrm{p}=0.682$ \\
\hline$\triangle \mathrm{HAQ}$ & $\beta=0.500$ & $\beta=0.428$ & $\beta=0.522$ & $\beta=0.201$ \\
\hline Arising & $\mathrm{p}=0.122$ & $\mathrm{p}=0.150$ & $p=0.036$ & $\mathrm{p}=0.471$ \\
\hline$\triangle \mathrm{HAQ}$ & $\beta=0.604$ & $\beta=0.439$ & $\beta=0.031$ & $\beta=0.065$ \\
\hline Eating & $p=0.040$ & $\mathrm{p}=0.120$ & $\mathrm{p}=0.920$ & $\mathrm{p}=0.800$ \\
\hline$\triangle \mathrm{HAQ}$ & $\beta=0.596$ & $\beta=0.181$ & $\beta=-0.077$ & $\beta=0.668$ \\
\hline Walking & $\mathrm{p}=0.058$ & $\mathrm{p}=0.549$ & $\mathrm{p}=0.791$ & $p=0.004$ \\
\hline$\triangle \mathrm{HAQ}$ & $\beta=0.259$ & $\beta=0.536$ & $\beta=0.368$ & $\beta=-0.216$ \\
\hline Hygiene & $\mathrm{p}=0.497$ & $\mathrm{p}=0.124$ & $\mathrm{p}=0.213$ & $\mathrm{p}=0.448$ \\
\hline$\triangle \mathrm{HAQ}$ & $\beta=0.409$ & $\beta=0.326$ & $\beta=0.364$ & $\beta=0.142$ \\
\hline Reach & $\mathrm{p}=0.174$ & $\mathrm{p}=0.286$ & $\mathrm{p}=0.223$ & $\mathrm{p}=0.584$ \\
\hline$\triangle \mathrm{HAQ}$ & $\beta=0.871$ & $\beta=0.345$ & $\beta=0.521$ & $\beta=0.119$ \\
\hline Grip & $p=0.002$ & $\mathrm{p}=0.237$ & $p=0.037$ & $\mathrm{p}=0.651$ \\
\hline$\triangle \mathrm{HAQ}$ & $\beta=0.138$ & $\beta=0.444$ & $\beta=0.123$ & $\beta=0.094$ \\
\hline Activities & $\mathrm{p}=0.715$ & $\mathrm{p}=0.210$ & $\mathrm{p}=0.722$ & $\mathrm{p}=0.756$ \\
\hline$\triangle \mathrm{MHQ}$ & $\beta=-0.237$ & $\beta=-0.464$ & $\beta=-0.553$ & $\beta=0.061$ \\
\hline Total & $\mathrm{p}=0.520$ & $\mathrm{p}=0.090$ & $p=0.033$ & $\mathrm{p}=0.827$ \\
\hline$\triangle \mathrm{MHQ}$ & $\beta=-0.796$ & $\beta=-0.225$ & $\beta=-0.133$ & $\beta=0.034$ \\
\hline $\mathrm{ADL}$ & $p=0.024$ & $\mathrm{p}=0.404$ & $p=0.678$ & $\mathrm{p}=0.897$ \\
\hline$\triangle \mathrm{MHQ}$ & $\beta=-0.089$ & $\beta=-0.250$ & $\beta=-0.259$ & $\beta=0.073$ \\
\hline Function & $\mathrm{p}=0.777$ & $\mathrm{p}=0.353$ & $\mathrm{p}=0.407$ & $p=0.776$ \\
\hline$\triangle \mathrm{MHQ}$ & $\beta=-0.149$ & $\beta=-0.396$ & $\beta=-0.299$ & $\beta=0.120$ \\
\hline Work performance & $p=0.739$ & $\mathrm{p}=0.251$ & $\mathrm{p}=0.454$ & $p=0.726$ \\
\hline$\triangle \mathrm{MHQ}$ & $\beta=-0.106$ & $\beta=-0.249$ & $\beta=-0.409$ & $\beta=0.060$ \\
\hline Aesthetics & $\mathrm{p}=0.791$ & $\mathrm{p}=0.468$ & $p=0.222$ & $\mathrm{p}=0.848$ \\
\hline$\triangle \mathrm{MHQ}$ & $\beta=0.785$ & $\beta=0.239$ & $\beta=0.704$ & $\beta=-0.075$ \\
\hline Pain & $p=0.025$ & $\mathrm{p}=0.464$ & $p=0.019$ & $\mathrm{p}=0.810$ \\
\hline$\triangle \mathrm{MHQ}$ & $\beta=-0.164$ & $\beta=-0.502$ & $\beta=-0.412$ & $\beta=-0.113$ \\
\hline Patient satisfaction & $\mathrm{p}=0.660$ & $p=0.048$ & $p=0.195$ & $p=0.654$ \\
\hline
\end{tabular}

Values in bold face are statistically significant. BME: bone marrow edema; JSV: joint space volume; ESR: erythrocyte sedimentation rate; CRP: C-reactive protein; MHQ: Michigan Hand Outcome Questionnaire; ADL: activities of daily living; DAS28: 28-joint count Disease Activity Score; HAQ: Health Assessment Questionnaire. 
study is the first to investigate the relationships between quantitative assessments using multimodality imaging (3T MRI and HR-pQCT) and clinical and functional assessments including DAS28, HAQ, and MHQ. In accordance with a significant decrease in clinical and functional assessments in the anti-TNF- $\alpha$ treatment group (synovitis volume, BME volume, and erosion volumes) as evaluated by quantitative measures, there were significant decreases and correlations with changes of clinical and functional assessments, suggesting that these changes are well-reflected in the clinical response. However, there were no differences in RAMRIS score within the first 3 months of treatment and no significant correlations between RAMRIS score and clinical and functional assessments, even though previous large cohort studies reported that RAMRIS score, especially synovitis and BME pattern, could detect early changes ${ }^{34,35,36}$. This suggests that RAMRIS may have limited sensitivity to subtle changes within short periods as a semiquantitative measure in small cohort studies. Therefore, these findings suggest that quantitative measures may be more sensitive than RAMRIS in detecting early and subtle changes, which may help reduce the required sample size for future clinical trials.

Interestingly, we also found that bone erosion progression was detected by HR-pQCT in MTX-only therapy within 3 months even with low disease activity. These findings are consistent with previous reports that show that patients with a low level of disease activity, and even those in clinical remission, can demonstrate progression of bone erosion, particularly if treated with conventional antirheumatic drugs $s^{37,38,39}$. Additionally, the significant increases in synovitis and BME volume from baseline to 3 months in the MTX-only group could support previous findings that progression of bone erosions in patients with clinical remission or low disease activity is a result of residual, subclinical synovitis and osteitis, which is sufficient to trigger continued osteoclast differentiation and bone erosions ${ }^{40}$. However, because the MTX group in this current study included the patients with remission and low disease activity, our findings in this current study that MTX-only therapy might induce joint destruction does not suggest that the MTX-only therapy has no effect in preventing bone destruction. Therefore, future studies would be necessary to compare the change of destruction between patients treated with MTX with remission and low disease activity. Moreover, although HR-pQCT-driven bone erosion volumes showed a decrease from baseline to 3 months after anti-TNF- $\alpha$ initiation, the RAMRIS erosion score did not show any change. Additionally, while MRI has a higher sensitivity in detecting erosions than radiographs and several studies showed RAMRIS erosion with significant changes over 6 months or longer ${ }^{17,41}$, our current study did not show significant changes in RAMRIS erosion. This difference could be explained by the short observational period in this study (3 mos) and that this study did not include the metacarpopha- langeal (MCP) joint in MRI scanning. A previous study showed that MRI has a lower sensitivity when compared to HR-pQCT when identifying bone erosions $(60 \%)$ and osteosclerosis $(24 \%)^{42}$. Although changes in RAMRIS erosions did not significantly correlate with changes in clinical and functional assessments, changes in bone erosion volume measured by HR-pQCT demonstrated significant correlations with changes in DAS28-CRP, HAQ-total, and MHQ-total. Therefore, when focusing on bone-related changes, HR-pQCT is a powerful tool that can provide objective and sensitive measures of bone erosions, and could be used as promising outcome measures in RA.

In patients with RA, functional disorders are dependent on disease activity and joint destruction ${ }^{43}$. This longitudinal study used the MHQ and HAQ scores to assess function. One recent cross-sectional study showed a significant relationship between the MHQ score and radiographic joint destruction in the hands of patients with RA, especially among those with low disease activity ${ }^{6}$. To our knowledge, our current study was the first to show the correlation between changes of MHQ score and detailed radiological assessments. Certainly, HAQ is the most common functional assessment for patients with RA, though HAQ can be influenced by aging ${ }^{44}$ and has ceiling effects ${ }^{6}$. Considering that MHQ is more specific to hand function, the use of MHQ assessments along with HAQ and radiological assessments could result in a stronger, more useful way to evaluate function.

Some limitations found in our study include the small sample size and short-term followup. First, owing to the small sample size, we did not have enough power to adjust for other potential confounding factors for patient outcomes; therefore, these results should be taken as exploratory. Larger cohort studies should be conducted to confirm these results. Second, we intended to examine the early structural changes after a short period of 3 months. A longer followup study of this cohort would be needed to help interpret the observations we have made and to further expand our understanding of the relationship between quantitative imaging changes with clinical and functional outcomes. Currently, this study cohort is undergoing a year-long followup, which may help confirm these results. Third, MRI imaging in our study did not include MCP joints. Because previous studies using RAMRIS included MCP joints, our findings will be tested and confirmed in future studies with data including both wrist and MCP joints. Fourth, this study design was not a randomized controlled study; therefore, future studies are necessary to investigate these structural assessments associated with the clinical and functional assessments in a randomized controlled study.

Advanced imaging measures of synovitis, BME, and erosion volume show promising potential to serve as biomarkers to determine disease progression, therapy response, and function in patients with RA after only 3 months. Quantitative evaluation appears more sensitive than

Personal non-commercial use only. The Journal of Rheumatology Copyright @ 2019. All rights reserved. 
semiquantitative grading for detecting subtle, short-term changes. A multimodality imaging approach with MRI and HR-pQCT may be powerful for evaluating early changes after treatment in RA.

\section{ACKNOWLEDGMENT}

We thank Stephanie Murphy and Grace Jun, clinical research coordinators, for supporting our study.

\section{REFERENCES}

1. McGonagle D, Conaghan PG, O'Connor P, Gibbon W, Green M, Wakefield $\mathrm{R}$, et al. The relationship between synovitis and bone changes in early untreated rheumatoid arthritis: A controlled magnetic resonance imaging study. Arthritis Rheum 1999; 42:1706-11.

2. Finckh A, Liang MH, van Herckenrode CM, de Pablo P. Long-term impact of early treatment on radiographic progression in rheumatoid arthritis: a meta-analysis. Arthritis Rheum 2006;55:864-72.

3. Nell VP, Machold KP, Eberl G, Stamm TA, Uffmann M, Smolen JS. Benefit of very early referral and very early therapy with disease-modifying anti-rheumatic drugs in patients with early rheumatoid arthritis. Rheumatology 2004;43:906-14

4. Singh JA, Saag KG, Bridges SL Jr, Akl EA, Bannuru RR, Sullivan MC, et al. 2015 American College of Rheumatology guideline for the treatment of rheumatoid arthritis. Arthritis Rheumatol 2016;68:1-26.

5. Chung KC, Pillsbury MS, Walters MR, Hayward RA. Reliability and validity testing of the Michigan Hand Outcomes Questionnaire. J Hand Surg Am 1998;23:575-87.

6. Yasui T, Oka H, Omata Y, Kadono Y, Tanaka S. Relationship between roentgenographic joint destruction in the hands and functional disorders among patients with rheumatoid arthritis. Mod Rheumatol 2017;27:828-32.

7. Dritsaki M, Petrou S, Williams M, Lamb SE. An empirical evaluation of the SF-12, SF-6D, EQ-5D and Michigan Hand Outcome Questionnaire in patients with rheumatoid arthritis of the hand. Health Qual Life Outcomes 2017;15:20.

8. van der Heijde DM, van Riel PL, Nuver-Zwart IH, Gribnau FW, vad de Putte LB. Effects of hydroxychloroquine and sulphasalazine on progression of joint damage in rheumatoid arthritis. Lancet 1989;1:1036-8.

9. Ostergaard M, Peterfy C, Conaghan P, McQueen F, Bird P, Ejbjerg $\mathrm{B}$, et al. OMERACT rheumatoid arthritis magnetic resonance imaging studies. Core set of MRI acquisitions, joint pathology definitions, and the OMERACT RA-MRI scoring system. J Rheumatol 2003;30:1385-6.

10. Hodgson RJ, O'Connor P, Moots R. MRI of rheumatoid arthritis image quantitation for the assessment of disease activity, progression and response to therapy. Rheumatology 2008;47:13-21.

11. Peterfy C, Ostergaard M, Conaghan PG. MRI comes of age in RA clinical trials. Ann Rheum Dis 2013;72:794-6.

12. American College of Rheumatology Rheumatoid Arthritis Clinical Trials Task Force Imaging Group, Outcome Measures in Rheumatology Magnetic Resonance Imaging Inflammatory Arthritis Working Group. Review: the utility of magnetic resonance imaging for assessing structural damage in randomized controlled trials in rheumatoid arthritis. Arthritis Rheum 2013;65:2513-23.

13. Ostergaard M, Peterfy CG, Bird P, Gandjbakhch F, Glinatsi D, Eshed I, et al. The OMERACT Rheumatoid Arthritis Magnetic Resonance Imaging (MRI) scoring system: updated recommendations by the OMERACT MRI in Arthritis Working Group. J Rheumatol 2017;44:1706-12.

14. Hetland ML, Ejbjerg B, Horslev-Petersen K, Jacobsen S, Vestergaard A, Jurik AG, et al; CIMESTRA study group. MRI bone oedema is the strongest predictor of subsequent radiographic progression in early rheumatoid arthritis. Results from a 2-year randomised controlled trial (CIMESTRA). Ann Rheum Dis 2009;68:384-90.

15. Baker JF, Conaghan PG, Emery P, Baker DG, Ostergaard M. Relationship of patient-reported outcomes with MRI measures in rheumatoid arthritis. Ann Rheum Dis 2017;76:486-90.

16. Glinatsi D, Baker JF, Hetland ML, Horslev-Petersen K, Ejbjerg BJ, Stengaard-Pedersen K, et al. Magnetic resonance imaging assessed inflammation in the wrist is associated with patient-reported physical impairment, global assessment of disease activity and pain in early rheumatoid arthritis: longitudinal results from two randomised controlled trials. Ann Rheum Dis 2017;76:1707-15.

17. Woodworth TG, Morgacheva O, Pimienta OL, Troum OM, Ranganath VK, Furst DE. Examining the validity of the rheumatoid arthritis magnetic resonance imaging score according to the OMERACT filter-a systematic literature review. Rheumatology 2017;56:1177-88.

18. Li X, Yu A, Virayavanich W, Noworolski SM, Link TM, Imboden J Quantitative characterization of bone marrow edema pattern in rheumatoid arthritis using 3 Tesla MRI. J Magn Reson Imaging 2012;35:211-7.

19. Yang H, Rivoire J, Hoppe M, Srikhum W, Imboden J, Link TM, et al. Computer-aided and manual quantifications of MRI synovitis, bone marrow edema-like lesions, erosion and cartilage loss in rheumatoid arthritis of the wrist. Skeletal Radiol 2015;44:539-47.

20. Bacchetta J, Boutroy S, Vilayphiou N, Fouque-Aubert A, Delmas PD, Lespessailles E, et al. Assessment of bone microarchitecture in chronic kidney disease: a comparison of 2D bone texture analysis and high-resolution peripheral quantitative computed tomography at the radius and tibia. Calcif Tissue Int 2010;87:385-91.

21. Zhu TY, Griffith JF, Qin L, Hung VW, Fong TN, Au SK, et al. Structure and strength of the distal radius in female patients with rheumatoid arthritis: a case-control study. J Bone Miner Res 2013;28:794-806.

22. Srikhum W, Virayavanich W, Burghardt AJ, Yu A, Link TM, Imboden JB, et al. Quantitative and semiquantitative bone erosion assessment on high-resolution peripheral quantitative computed tomography in rheumatoid arthritis. J Rheumatol 2013;40:408-16.

23. Kocijan R, Finzel S, Englbrecht M, Engelke K, Rech J, Schett G. Decreased quantity and quality of the periarticular and nonperiarticular bone in patients with rheumatoid arthritis: A cross-sectional HR-pQCT study. J Bone Miner Res 2014; 29:1005-14

24. Teruel JR, Burghardt AJ, Rivoire J, Srikhum W, Noworolski SM, Link TM, et al. Bone structure and perfusion quantification of bone marrow edema pattern in the wrist of patients with rheumatoid arthritis: a multimodality study. J Rheumatol 2014;41:1766-73.

25. Shimizu T, Choi HJ, Heilmeier U, Tanaka M, Burghardt AJ, Gong J, et al. Assessment of 3-month changes in bone microstructure under anti- TNF $\alpha$ therapy in patients with rheumatoid arthritis using high-resolution peripheral quantitative computed tomography (HR-pQCT). Arthritis Res Ther 2017;19:222.

26. Aletaha D, Neogi T, Silman AJ, Funovits J, Felson DT, Bingham CO 3rd, et al. 2010 rheumatoid arthritis classification criteria: an American College of Rheumatology/European League Against Rheumatism collaborative initiative. Arthritis Rheum 2010; 62:2569-81

27. Prevoo ML, van 't Hof MA, Kuper HH, van Leeuwen MA, van de Putte LB, van Riel PL. Modified disease activity scores that include twenty-eight-joint counts. Development and validation in a prospective longitudinal study of patients with rheumatoid arthritis Arthritis Rheum 1995;38:44-8.

28. Bruce B, Fries JF. The health assessment questionnaire (HAQ). Clin Exp Rheumatol 2005;5 Suppl 39:S14-8. 
29. Durmus D, Uzuner B, Durmaz Y, Bilgici A, Kuru O. Michigan Hand Outcomes Questionnaire in rheumatoid arthritis patients: relationship with disease activity, quality of life, and handgrip strength. J Back Musculoskelet Rehabil 2013;26:467-73.

30. MacNeil JA, Boyd SK. Improved reproducibility of high-resolution peripheral quantitative computed tomography for measurement of bone quality. Med Eng Phys 2008;30:792-9.

31. Barnabe C, Feehan L; SPECTRA (Study GrouP for XTrEme-CT in RA). High-resolution peripheral quantitative computed tomography imaging protocol for metacarpophalangeal joints in inflammatory arthritis: The SPECTRA collaboration. J Rheumatol 2012; 39:1494-5.

32. Burghardt AJ, Lee CH, Kuo D, Majumdar S, Imboden JB, Link TM, et al. Quantitative in vivo HR-pQCT imaging of 3D wrist and metacarpophalangeal joint space width in rheumatoid arthritis. Ann Biomed Eng 2013;41:2553-64.

33. Wells G, Becker JC, Teng J, Dougados M, Schiff M, Smolen J, et al. Validation of the 28-joint Disease Activity Score (DAS28) and European League Against Rheumatism response criteria based on $\mathrm{C}$-reactive protein against disease progression in patients with rheumatoid arthritis, and comparison with the DAS28 based on erythrocyte sedimentation rate. Ann Rheum Dis 2009;68:954-60.

34. Conaghan PG, Emery P, Ostergaard M, Keystone EC, Genovese MC, Hsia EC, et al. Assessment by MRI of inflammation and damage in rheumatoid arthritis patients with methotrexate inadequate response receiving golimumab: results of the GO-FORWARD trial. Ann Rheum Dis 2011;70:1968-74.

35. Ostergaard M, Emery P, Conaghan PG, Fleischmann R, Hsia EC, $\mathrm{Xu} \mathrm{W}$, et al. Significant improvement in synovitis, osteitis, and bone erosion following golimumab and methotrexate combination therapy as compared with methotrexate alone: a magnetic resonance imaging study of 318 methotrexate-naive rheumatoid arthritis patients. Arthritis Rheum 2011;63:3712-22.

36. Haavardsholm EA, Ostergaard M, Ejbjerg BJ, Kvan NP, Uhlig TA, Lilleas FG, et al. Reliability and sensitivity to change of the OMERACT rheumatoid arthritis magnetic resonance imaging score in a multireader, longitudinal setting. Arthritis Rheum 2005;52:3860-7.
37. Molenaar ET, Voskuyl AE, Dinant HJ, Bezemer PD, Boers M, Dijkmans BA. Progression of radiologic damage in patients with rheumatoid arthritis in clinical remission. Arthritis Rheum 2004;50:36-42.

38. Cohen G, Gossec L, Dougados M, Cantagrel A, Goupille P, Daures JP, et al. Radiological damage in patients with rheumatoid arthritis on sustained remission. Ann Rheum Dis 2007;66:358-63.

39. Brown AK, Conaghan PG, Karim Z, Quinn MA, Ikeda K, Peterfy $\mathrm{CG}$, et al. An explanation for the apparent dissociation between clinical remission and continued structural deterioration in rheumatoid arthritis. Arthritis Rheum 2008;58:2958-67.

40. Schett G, Gravallese E. Bone erosion in rheumatoid arthritis: mechanisms, diagnosis and treatment. Nat Rev Rheumatol 2012;8:656-64.

41. Cohen SB, Dore RK, Lane NE, Ory PA, Peterfy CG, Sharp JT, et al; Denosumab Rheumatoid Arthritis Study Group. Denosumab treatment effects on structural damage, bone mineral density, and bone turnover in rheumatoid arthritis: a twelve-month, multicenter, randomized, double-blind, placebo-controlled, phase II clinical trial. Arthritis Rheum 2008;58:1299-309.

42. Regensburger A, Rech J, Englbrecht M, Finzel S, Kraus S, Hecht K, et al. A comparative analysis of magnetic resonance imaging and high-resolution peripheral quantitative computed tomography of the hand for the detection of erosion repair in rheumatoid arthritis. Rheumatology 2015;54:1573-81.

43. Drossaers-Bakker KW, de Buck M, van Zeben D, Zwinderman AH, Breedveld FC, Hazes JM. Long-term course and outcome of functional capacity in rheumatoid arthritis: The effect of disease activity and radiologic damage over time. Arthritis Rheum 1999;42:1854-60.

44. Sokka T, Kautiainen H, Hannonen P, Pincus T. Changes in Health Assessment Questionnaire disability scores over five years in patients with rheumatoid arthritis compared with the general population. Arthritis Rheum 2006;54:3113-8. 